Shyness, alcohol use disorders and 'hangxiety': A naturalistic study of social drinkers

Short title: "Hangxiety" and shyness in social drinkers

Beth Marsh ${ }^{1,2}$, Molly Carlyle ${ }^{1}$, Emily Carter ${ }^{1}$, Paige Hughes ${ }^{1}$, Sarah McGahey ${ }^{1}$, Will Lawn ${ }^{2}$, Tobias Stevens ${ }^{1}$, Amy McAndrew ${ }^{1}$, Celia JA Morgan ${ }^{1,2}$

${ }^{1}$ Psychopharmacology and Addiction Research Centre, University of Exeter, UK

${ }^{2}$ Clinical Psychopharmacology Unit, University College London, UK

*Address correspondence to:

Beth Marsh

Clinical Psychopharmacology Unit

1-19 Torrington Place

University College London

London

WC1E 7HB

b.marsh@ucl.ac.uk

Key words: Alcohol, social anxiety, hangover, shyness, alcohol use disorders 


\title{
Shyness, alcohol use disorders and 'hangxiety': A naturalistic study of social drinkers
}

\section{Word count: 5000}

\begin{abstract}
Social anxiety disorder (SAD) has been related to alcohol use disorder (AUD). Shyness can be considered a subclinical analogue of SAD, yet there is little research into the effect of alcohol on anxiety levels in highly-shy individuals. This naturalistic study investigated acute and sub-acute effects of alcohol in high and low shy social drinkers. 97 individuals were tested at home and assigned to either consume alcohol to normal levels $(n=50)$ or to remain sober $(n=47)$. Baseline measures of AUD symptoms, shyness and social phobia were taken. Measures of state anxiety were taken at baseline, following a period of alcohol consumption or sobriety, and the following morning. Marginally decreased acute anxiety resulting from alcohol consumption in high shyness was observed. A significant increase in anxiety the day following drinking was observed in highly-shy participants. There was a significant correlation between anxiety elevation on the second day and AUDIT scores in highly-shy participants. This study suggests anxiety during hangover is linked to AUD symptoms in highly-shy individuals, providing a potential marker for increased AUD risk, which could inform prevention and treatment.
\end{abstract}




\section{Introduction}

Alcohol use disorders (AUD) are a worldwide health concern with many associated health and social problems (Grant et al., 2015; NHS, 2013). Social anxiety disorder (SAD) is a risk factor for AUD development, with findings from a US survey indicating SAD precedes AUD in $80 \%$ of co-morbid cases (Schneier et al., 2010). Shyness is a common sub-clinical term used to describe anxiety and inhibition in social situations, and shares cognitive, behavioural and physical symptoms with SAD including negative self-evaluation, worries about the evaluation of others, sweating, elevated heart rate and withdrawal from social interactions (Cheek, 2007). Thus, shyness can be conceptualised on a continuum with $\mathrm{SAD}$, differing primarily in severity. While $\mathrm{SAD}$ and shyness share behavioural, cognitive and physiological symptoms, shyness is less debilitating, resulting in relatively less social avoidance (Santesso, Schmidt \& Fox, 2004). This reduced avoidance may increase the opportunity to use alcohol to manage symptoms of shyness. While SAD affects roughly $4 \%$ of the population, estimates of shyness prevalence range from 20-48\% (Heiser, Turner \& Beidel, 2003). Despite the increased prevalence associated with shyness, it has received significantly less attention in the literature than $\mathrm{SAD}$, with few studies exploring the relationship between shyness and alcohol use.

In previous work, students categorised as problem drinkers scored more highly on measures of shyness than non-problem drinkers, giving indication of a shyness-AUD link (Lewis \& O'Neil, 2000). Shyness has also been positively associated with alcohol-related problems across time (Young et al., 2015). Echoing conceptually related SAD research, coping motivated drinking has been shown to mediate links between AUD and shyness (Buckner et al., 2012; Cooper, 1994). With a paucity of literature relating AUD directly to shyness, anxiety theory and research is key to our understanding of their association. One potential underlying factor is the effect of alcohol on anxiety. 
During intoxication, alcohol can produce anxiolysis. As an indirect GABA agonist alcohol increases inhibitory GABAergic neurotransmission, and produces an associated decrease in excitatory glutamatergic transmission (Koob \& Weiss, 1992; Smith \& Randall, 2012). Animal studies demonstrate that alcohol facilitates GABA release in the amygdala - a region associated with responding to threat (Robinson, Alexander, Bluett, Patel \& McCool, 2015; Weiner \& Valenzuela, 2006). In humans, placebo-controlled fMRI research has indicated alcohol intoxication leads to both inhibited amygdala response and decreased behavioural responding to threatening stimuli (Gilman et al., 2008). Thus, alcohol may reduce anxiety by inhibiting responding to anxiety provoking stimuli.

The anxiolytic effect of alcohol may influence the SAD-AUD link and is thought to mediate coping-motivated drinking (Buckner et al., 2013). Self-report data and animal studies indicate highly anxious individuals are particularly susceptible to alcohol-induced anxiolysis (Henniger et al., 2002; Thomas, Randall \& Carrigan, 2003). This effect may negatively reinforce repeated alcohol use and increases AUD risk, particularly if consumption takes place in anxiety provoking circumstances (Khantzian, 1997; Carrigan \& Randall, 2003). Shy individuals may therefore be more vulnerable to repeated self-medication and resulting AUD risk due to the prevalence of alcohol in social settings. This assertion is supported by demonstrated links between SAD, coping motivated drinking and AUD (Buckner et al., 2012; Schry \& White, 2013).

Alcohol consumption can lead to increased anxiety during withdrawal, or 'hangover' - known in popular culture as 'hangxiety'. Compensatory down-regulation of GABA receptors and upregulation of glutamate receptors following alcohol exposure may underlie this effect (Riaza Bermudo-Soriano et al., 2012; Strużyńska \& Sulkowski, 2004). Hangxiety has been demonstrated in animal research, with mice exhibiting increased anxiety-related behaviours during ethanol hangover (Karadayian, Busso, Feleder \& Cutera, 2013). Furthermore, in one study of college students, increased anxiety was observed the morning after a normal night's drinking, compared with a night of sobriety 
(McKinney \& Coyle, 2006). Hangxiety may also play a role in the SAD-AUD link. According to the withdrawal-relief model, hangover represents an acute withdrawal syndrome which negatively reinforces alcohol use and is more pronounced in high AUD risk groups (Newlin \& Pretorious, 1990). Span and Earleywine (1999) demonstrated that sons of alcoholics report greater hangover symptoms than sons of non- alcoholics. Similarly, socially anxious individuals may experience more severe hangover symptoms - particularly hangxiety. Johnston et al. (1991) found that individuals with AUD and SAD experienced greater anxiogenic effects during hangover than individuals with AUD alone. Increased hangxiety may lead to greater negative reinforcement and increased AUD risk. Animal research demonstrates that anxiety levels during hangover positively correlate with later voluntary alcohol drinking among high anxiety phenotype rats (Ezequiel-Leite \& Nobre, 2012). Thus, hangxiety may influence the SAD/shyness-AUD link.

Despite the relationship between SAD and shyness, no work has looked at the effects of alcohol on anxiety as a function of shyness. Influenced by research linking anxiety to AUD via negative reinforcement of both acute anxiolysis and hangxiety, the present study investigated these effects as a function of shyness. Existing work suggests the effects of alcohol on mood observed naturalistically are not replicated in the lab (Kirkpatrick \& de Wit, 2013; Lindman, 1982). This study, therefore, employed a naturalistic design with ad libitum alcohol consumption. It was predicted that alcohol consumption would result in acute anxiolysis, followed by a subsequent rebound in anxiety during hangover, and that these effects would be increased in people who were more shy. Finally, it was predicted that the anxiolytic effects of alcohol and anxiogenic effects of hangover may be related to AUD symptoms among those scoring higher on shyness. 


\section{Materials and Methods}

\section{Design and participants}

The experiment took place over two consecutive days with a two-session, pseudo-randomised mixed within and between participants design. Due to the naturalistic design used, participants and experimenters were not blinded to condition (alcohol; sober). Participants were self-classified social drinkers aged 18+. 62 females and 35 males aged 18-53 were recruited via opportunity and snowball sampling. Groups were matched for gender, with 30 females and 17 males in the sober group, and 32 females and 18 males in the alcohol group. Exclusion criteria were: severe symptoms of social phobia (indicated by a score of $>40$ on the Social Phobia Inventory), regular prescribed medication (other than contraceptives), neurological or relevant psychiatric/physical condition, confirmed or suspected pregnancy, current suicidal ideation, a BMI of $>35$ or $<16$. All participants were asked not to use alcohol or recreational drugs for 24 hours or eat for two hours prior to session one. This research was approved by the institutional Ethics Committee.

\section{Procedure}

Experimental sessions took place in the participants' homes. Session 1 was conducted while participants socialised with friends, session 2 the following morning. To maximise the ecological validity of the naturalistic design, session 1 was conducted during an occasion of socialising at home which was already arranged and not orchestrated for the purposes of the experiment. See figure 1 for a schematic outline.

$<$ Insert Figure 1 about here $>$ 
Session 1 and Alcohol Administration._This session began at 6pm and lasted four hours.

Experimenters remained in the participants homes throughout. Consent was received before a screening questionnaire was completed. A baseline breathalyser reading was taken and demographic information was gathered before baseline questionnaires pertaining to shyness, social phobia and state anxiety.

Next, participants in the alcohol condition were instructed to socialise normally and consume alcohol ad libitum for 2 hours, while those in the sober condition were instructed to socialise normally whilst consuming no alcohol. After 2 hours, participants in the alcohol condition estimated the number of units they had consumed and all participants completed a further state anxiety measure. Finally a second breathalyser reading was taken. Participants in the alcohol condition then continued drinking ad libitum while participants in the sober group were instructed to consume no alcohol.

Session 2. This session began at 10am and lasted one hour. A breathalyser reading was taken before measures pertaining to state anxiety and alcohol use disorder risk. Information regarding drug and alcohol behaviours was gathered and participants estimated the total amount of alcohol they consumed the previous evening. Participants were then fully debriefed and paid $£ 5$.

\section{Assessments}

Social Phobia Inventory. (SPIN; Connor et al, 2000) This psychometrically validated 17-item scale (Antony et al, 2006) was used to control for clinical levels of SA. Items (e.g. 'I avoid talking to people I don't know') are self-scored on a five-point scale from $0=$ 'not at all' to 4 = 'extremely'. Participants scoring $>40(n=7)$ - indication of severe-very severe symptoms - were excluded from analyses. 
Shyness Scale. (Cheek \& Melchior, 1985) This psychometrically validated 20-item measure (Melchior \& Cheek, 1990), developed to assess cognitive, affective and behavioural components of shyness was used to assess trait shyness. Items (e.g. 'I feel relaxed even in unfamiliar situations') are self-scored on a five-point scale from $1=$ 'strongly disagree' to $5=$ 'strongly agree'.

State-Trait Anxiety Inventory. (STAI; Spielberger, Gorsuch, Lushene, Vagg \& Jacobs, 1983; Appendix E) The state form of this psychometrically validated 20-item measure was used to assess changes in anxiety from baseline to intoxication and hangover (Brenneisen et al., 2016). The scale consists of polarised items relating to the construct of anxiety such as 'I feel secure' and 'I am tense' are self-rated on a four-point scale from $1=$ 'not at all' to $4=$ 'very much so'.

Alcohol Use Disorder Identification Test. (AUDIT; Babor, de la Fuente, Saunders, \& Grant, 1992). This psychometrically validated 10 -item measure, developed to screen for indicators of longterm alcohol use problems (de Meneses-Gaya et al., 2009), was used to assess participants' AUD symptoms. Items (e.g. 'How often do you have a drink containing alcohol' and 'How often during the last year have you had a feeling of guilt or remorse after drinking') are self-scored from 0-4.

Breathalysers (Alcosafe Digital Alcohol Breath Tester kx6000S) were used throughout as a manipulation check for condition. A blood alcohol concentration percentage (BAC) is calculated from breath alcohol content (BrAC), using the conventional UK BrAC:BAC ratio of 1:23000 (Department for Transport, 2010).

\section{Statistical Analyses}

All data were analysed using SPSS version 22. Skewness and Kurtosis were tested and the data inspected for outliers. 
To assess matching of the groups, independent samples t-tests were used for parametric data and Chi-square tests for categorical data. As a measure of the relationship between social anxiety and shyness, Pearson's correlations were performed on total SPIN and total Shyness scale scores. To assess differences in the amount of alcohol consumed during the experiment, independent samples ttests were conducted on estimated units and drinks consumed by low-shy and high-shy participants in the alcohol group.

A median split was used to divide participants into low and high shyness groups. To analyse changes in STAI score during intoxication and hangover, a 3 × 2 × 2 Repeated Measures ANOVA was used with one within-subjects factor: Experimental stage (T1; baseline/T2; immediately following drinking/T3; hangover) and two between-subjects factors: Condition (Sober/Alcohol) and Shyness level (Low/High). The Huyn-Feldt correction for sphericity was applied to within-subjects factors when necessary and Bonferroni corrected post-hoc tests used to explore significance.

To investigate potential links between alcohol-related changes in anxiety and AUD symptoms, Pearson's correlations were performed on parametric data and Spearman's correlations on non-parametric data from both high and low shyness alcohol groups. The data included were: AUDIT total, change in anxiety from $\mathrm{T} 1$ to $\mathrm{T} 2$ and change in anxiety from $\mathrm{T} 2$ to $\mathrm{T} 3$.

Alcohol manipulation checks were performed on breathalyser data using the non-parametric Mann-Whitney U test.

\section{Results}

\section{Participant characteristics}

Groups were matched on multiple demographic factors, alcohol consumption behaviours, tobacco use, family history of diagnosed AUD and mental health problems and baseline assessment scores. The alcohol group had spent significantly more years of education than the control group (see Table 1). 
$<$ Insert Table 1 about here $>$

\section{Alcohol use during the study}

Whole sample

Among participants in the alcohol condition, there were no significant shyness group differences in the number of units/drinks consumed either during the two-hour drinking period prior to the second anxiety measure, or throughout the evening. The sober group reported no alcohol use (Table 2).

$<$ Insert Table 2 about here $>$

\section{Shyness, anxiety and condition}

There was a three-way interaction between Experimental stage, Condition and Shyness level on STAI scores $\left(F(2,182)=3.388, p=.036, \eta_{2}=.036\right)($ Figure 2$)$. There was a two-way interaction between Experimental stage and Condition $\left(F(2,182)=6.994, p=.001, \eta_{2}=.071\right)$. There was a main effect of Experimental stage $\left(F(2,182)=3.717, p=.026, \eta_{2}=.039 ;\right.$ means $-\mathrm{T} 1: 39.705 \pm 6.914 ; \mathrm{T} 2: 38.358 \pm$ 6.796; T3: $39.968 \pm 7.413)$, and also a main effect of Shyness level $\left(F(1,91)=6.319, p=.014, \eta^{2}\right.$ $=.065$; means - Low shy: $39.519 \pm 8.748$; High shy: $64.333 \pm 8.868)$. To explain the Experimental stage $\mathrm{x}$ Condition $\mathrm{x}$ Shyness level interaction, paired samples t-tests (Bonferroni corrected alpha .006) were conducted. There was a significant decrease in anxiety scores from $\mathrm{T} 1(\mathrm{M}=41.68, \mathrm{SD}=6.65)$ to $\mathrm{T} 3(\mathrm{M}=38.36, \mathrm{SD}=4.319)$ in the high-shy sober group $(t(24)=3.058, p=.005)$. There was also a significant increase in anxiety from $\mathrm{T} 2(\mathrm{M}=38.5, \mathrm{SD}=6.279)$ to $\mathrm{T} 3(\mathrm{M}=44.8, \mathrm{SD}=8.776)$ in the high-shy alcohol group $(t(19)=-3.268, p=.004)$. There was also a trend towards a decrease in anxiety from $\mathrm{T} 1(\mathrm{M}=41.7, \mathrm{SD}=8.151)$ to $\mathrm{T} 2(\mathrm{M}=38.5, \mathrm{SD}=6.279)$ in the high shy alcohol group $(t(19)=2.288, p=.034)$. No other significant comparisons were observed. Higher levels of shyness were therefore associated with decreased anxiety from baseline to 'hangover' among those who 
remained sober, and with increased anxiety from intoxication to hangover in those who consumed alcohol.

$<$ Insert Figure 2 about here $>$

\section{Shyness, anxiety and AUD symptoms}

No significant relationship was observed between change in anxiety from baseline to intoxication and AUDIT total in either the Low shy $(r(29)=.207, p=.282)$ or High shy $(r(20)=-.280, p=.233)$ group. There was no significant relationship between change in anxiety from intoxication to hangover ('hangxiety') and AUDIT total among participants in the Low shy alcohol group $(r(29)=.082, p=$ .673). There was a moderate positive relationship, between hangxiety and AUDIT total among participants in the High shy alcohol group $\left(r_{s}(20)=.472, p=.036\right)$ (Figure 3). Increased AUD symptoms were therefore associated with a greater rebound in anxiety during alcohol hangover, among those categorised as high shy.

$<$ Insert Figure 3 about here $>$

\section{Manipulation checks.}

Mann-Whitney $\mathrm{U}$ tests were conducted to test for significant differences in BrAC readings across breathalyser recordings. There was no group difference in breathalyser reading at baseline (breathalyser 1). Scores on the second breathalyser, taken after the period of socialising with or without alcohol, were significantly greater in the Alcohol condition $(M d n=.115, I Q R=.275)$ than the Sober condition $(M d n=.00, I Q R=.000)(U=31.00, p<.001)$. Scores on the third breathalyser, taken during the hangover phase, were significantly greater in the Alcohol condition $(M d n=.00, I Q R=$ $.125)$ than the Sober condition $(M d n=.00, I Q R=.000)(U=700, p<.001)$. 
This naturalistic study investigated whether the effects of alcohol on anxiety during intoxication and hangover differ as a function of shyness, exploring possible links to Alcohol Use Disorder (AUD) symptoms. Increased anxiety was observed during alcohol hangover among those scoring more highly on the shyness scale. There was a trend towards a positive association between hangxiety and AUD symptoms among high-shy participants in the alcohol group. Contrary to prediction, there was no significant reduction in anxiety during intoxication in the alcohol group, and this effect did not differ as a function of shyness. We did not find evidence in favour of an association between reduction in anxiety during intoxication and AUD symptoms among high or low shy participants.

As predicted, increased anxiety during hangover was observed among participants in the high-shy alcohol group - indicating that increases in anxiety observed during alcohol hangover may be further influenced by shyness (McKinney and Coyle, 2006). A similar number of drinks and units were consumed across the sample, indicating that the hangxiety effect was not due to greater alcohol consumption among highly-shy individuals. The similarities between these findings and conceptually related findings on SAD (Johnston et al., 1991), as well as a strong positive relationship between shyness and social anxiety measures, support qualitative links between the two and give credibility to the investigation of shyness as a sub-clinical manifestation of SAD.

In accordance with the withdrawal-relief model, the hangxiety effect observed suggests that highly shy individuals may be at increased AUD risk (Newlin \& Pretorius, 1990). This is given tentative support by the finding of an association, which approached significance, between hangxiety and AUD symptoms among shy participants in the alcohol group. This study therefore indicates that withdrawal-relief may influence the link between shyness and alcohol related problems.

There was a trend towards a reduction in anxiety from baseline to intoxication in highly-shy participants, and no difference in the other groups. These acutely gathered self-report data therefore 
do not echo previous animal and human fMRI data which demonstrate reduced anxious responding following alcohol consumption (Robinson et al., 2015; Gilman et al., 2008); nor retrospective selfreport data demonstrating greater alcohol-induced anxiolysis in anxious participants (Thomas et al., 2003).

Participants in this study consumed their drinks of choice in a familiar environment, at their chosen rate. A large proportion of alcohol studies are conducted in laboratory settings, where social context is absent (McKinney \& Coyle, 2006). The present design also allowed for the effects of a greater dose of alcohol to be observed than many alcohol studies, with participants consuming an average of 3.05 units above the number considered a 'binge dose' for males (NHS, 2013). These results are, therefore, more reliably representative of real-world alcohol effects than many studies. Another strength of this study is the exclusion of participants exhibiting clinically significant symptoms of social anxiety from analyses, allowing for more confident assertion that the effects observed are attributable to shyness.

This study has a number of limitations including the use of median split to categorise participants. Though parsimonious, this technique results in similar values around the median being treated as notably different. Alternative options include analysing the data using ANCOVA or linear regression, or trichotomising the sample on the basis of shyness and remove the middle group from analyses. The neurobiologically anxiolytic effects of alcohol are greatest at peak BAC. In this study, anxiety was measured after 2 hours of alcohol consumption, with participants drinking an average further 8.47 estimated units. Measuring anxiety while BAC is still rising may mask the anxiolytic effects of alcohol as the stimulating effects are more salient. The use of interval-contingent experience sampling, via smartphone app or other device, would allow for anxiety to be measured closer to peak BAC. This study also employed a cross-sectional design, limiting the opportunity for inferences regarding the direction of the relationships observed. Finally, no predictions were made regarding anxiety among participants in the sober condition, limiting the potential for interpretations of the 
observed decrease in anxiety among participants in the high shy sober condition from baseline to hangover.

The findings of this study support the withdrawal-relief model of problematic alcohol use among shy individuals. This research therefore indicates possible motives and high risk situations for shy individuals with AUD symptoms, which may be usefully considered in group and individualized addiction treatments. These findings also suggest benefit in targeting shy individuals for instance through awareness raising during campaigns like 'Dry January' which encourage individuals to reevaluate their relationship with alcohol (Ballard, 2015). Future research should clarify the mechanisms underlying the hangxiety effect observed, for instance the potential role of rumination and post-event processing (Clark \& Wells, 1995), and the role of coping motivated drinking, which was not directly assessed here, and may mediate the relationship between hanxiety and AUD symptoms among shy individuals. 
Antony, M. M., Coons, M. J., McCabe, R. E., Ashbaugh, A., \& Swinson, R. P. (2006). Psychometric properties of the social phobia inventory: Further evaluation. Behaviour Research and Therapy, 44(8), 1177-1185. https://doi.org/10.1016/j.brat.2005.08.013

Babor, T. F., De La Fuente, J. R., Saunders, J. \& Grant, M. (1992). AUDIT: The Alcohol Use Disorders Identification Test: Guidelines for use in Primary Health Care. Geneva, Switzerland: World Health Organization.

Brenneisen Mayer, F., Souza Santos, I., Silveira, P. S. P., Itaqui Lopes, M. H., de Souza, A. R. N. D., Campos, E. P., ... Tempski, P. (2016). Factors associated to depression and anxiety in medical students: a multicenter study. BMC Medical Education, 16, 282. http://doi.org/10.1186/s12909-016-0791-1

Buckner, J., Heimberg, R., Ecker, A., \& Vinci, C. (2012). A Biopsychosocial Model of Social Anxiety and Substance Use. Depression And Anxiety, 30(3), 276-284. http://dx.doi.org/10.1002/da.22032

Carrigan, M. \& Randall, C. (2003). Self-medication in social phobia: A review of the alcohol literature. Addictive Behaviors, 28(2), 269-284. http://dx.doi.org/10.1016/s0306$\underline{4603(01) 00235-0}$

Cheek, J. (2007). Shyness. In R. F. Baumeister \& K. D. Vohs (Eds.), Encyclopedia of social psychology (Vol. 1, pp. 875-875). Thousand Oaks, CA: SAGE Publications, Inc. doi: $10.4135 / 9781412956253 . n 516$

Cheek, J. M., \& Melchior, L. A. (1985). Measuring the three components of shyness. In M. H. Davis \& DS. L. Franzoi (Co-chairs), Emotion, personality, and personal well-being II. Symposium conducted at the annual convention of the American Psychological Association, Los Angeles, CA.

Clark, D. M., \& Wells, A. (1995). A cognitive model of social phobia. In R. Heimberg, M. Liebowitz, D. A. Hope, \& F. R. Schneier (Eds.), Social phobia: Diagnosis, assessment and treatment (pp. 
69-93). New York: Guildford Press.

Connor, K., Davidson, J., Churchill, L., Sherwood, A., Weisler, R., \& Foa, E. (2000). Psychometric properties of the Social Phobia Inventory (SPIN): New self-rating scale. The British Journal Of Psychiatry, 176(4), 379-386. doi: 10.1192/bjp.176.4.379

Cooper, M. (1994). Motivations for alcohol use among adolescents: Development and validation of a four-factor model. Psychological Assessment, 6(2), 117-128. http://dx.doi.org/10.1037/1040$\underline{3590.6 .2 .117}$

de Meneses-Gaya, C., Zuardi, A. W., Loureiro, S. R., \& Crippa, J. A. S. (2009). Alcohol Use Disorders Identification Test (AUDIT): An updated systematic review of psychometric properties. Psychology \& Neuroscience, 2(1), 83-97.

http://dx.doi.org/10.3922/j.psns.2009.1.12

Department for Transport,. (2010). Enforcement Procedures against Drink Drivers and Other Offenders - A Consultation Document (p. 20). London: Crown.

Ezequiel Leite, L. \& Nobre, M. (2012). The negative effects of alcohol hangover on high-anxiety phenotype rats are influenced by the glutamate receptors of the dorsal midbrain. Neuroscience, 213, 93-105. http://dx.doi.org/10.1016/j.neuroscience.2012.04.009

Gilman, J., Ramchandani, V., Davis, M., Bjork, J., \& Hommer, D. (2008). Why We Like to Drink: A Functional Magnetic Resonance Imaging Study of the Rewarding and Anxiolytic Effects of Alcohol. Journal Of Neuroscience, 28(18), 4583-4591. http://dx.doi.org/10.1523/jneurosci.0086-08.2008

Grant, B., Goldstein, R., Saha, T., Chou, S., Jung, J., \& Zhang, H. et al. (2015). Epidemiology of DSM-5 Alcohol Use Disorder. JAMA Psychiatry, 72(8), 757. http://dx.doi.org/10.1001/jamapsychiatry.2015.0584

Grant, B., Hasin, D., Blanco, C., Stinson, F., Chou, S., \& Goldstein, R. et al. (2005). The 
Epidemiology of Social Anxiety Disorder in the United States. J. Clin. Psychiatry, 66(11), 1351-1361. http://dx.doi.org/10.4088/jcp.v66n1102

Heiser, N., Turner, S., \& Beidel, D. (2003). Shyness: relationship to social phobia and other psychiatric disorders. Behaviour Research And Therapy, 41(2), 209-221. http://dx.doi.org/10.1016/s0005-7967(02)00003-7

Henniger, M., Spanagel, R., Wigger, A., Landgraf, R., \& Holter, S. (2002). Alcohol Selfadministration in Two Rat Lines Selectively Bred for Extremes in Anxiety-related Behavior. Neuropsychopharmacology, 26(6), 729-736. http://dx.doi.org/10.1016/s0893-133x(01)00408-0 Johnston, A. L., Thevos, A.K., Randall, C.L., Anton, R.F. (1991). Increased severity of alcohol withdrawal in in-patient alcoholics with a co-existing anxiety diagnosis. British Journal of Addictions 86, 719-725

Karadayian, A. G., Busso, M. J., Feleder, C., \& Cutrera, R. A. (2013). Alterations in affective behavior during the time course of alcohol hangover. Behavioural brain research, 253, 128-138. Khantzian, E. (1997). The Self-Medication Hypothesis of Substance Use Disorders: A Reconsideration and Recent Applications. Harv Rev Psychiatry, 4(5), 231-244. http://dx.doi.org/10.3109/10673229709030550

Kirkpatrick, M. G., \& de Wit, H. (2013). In the company of others: social factors alter acute alcohol effects. Psychopharmacology, 230(2), 215-226.

Koob, G.F., \& Weiss, F. (1992). Neuropharmacology of cocaine and ethanol dependence. Recent Developments in Alcoholism, 10, 201-233.

Lewis, B. A., \& O'Neill, H. K. (2000). Alcohol expectancies and social deficits relating to problem drinking among college students. Addictive Behaviors, 25, 295-299.

Lindman, R. (1982). Social and solitary drinking: effects on consumption and mood in male social drinkers. Physiology \& behavior, 28(6), 1093-1095.

McKinney, A., \& Coyle, K. (2006). Alcohol hangover effects on measures of affect the morning after 
a normal night's drinking. Alcohol And Alcoholism, 41(1), 54-60.

http://dx.doi.org/10.1093/alcalc/agh226

Melchior, L.A., \& Cheek, J.M. (1990). Shyness and anxious self-preoccupation during a social interaction. Journal of Social Behavior and Personality, 5, 117-130.

National Health Service (NHS). (2013). Alcohol Misuse. Retrieved 25 November, 2015, from http://www.nhs.uk/conditions/Alcohol-misuse/Pages/Introduction.aspx

Newlin, D. \& Pretorius, M. (1990). Sons of Alcoholics Report Greater Hangover Symptoms than Sons of Nonalcoholics: A Pilot Study. Alcoholism: Clinical And Experimental Research, 14(5), 713-716. http://dx.doi.org/10.1111/j.1530-0277.1990.tb01231.x

Riaza Bermudo-Soriano, C., Perez-Rodriguez, M., Vaquero-Lorenzo, C., \& Baca-Garcia, E. (2012). New perspectives in glutamate and anxiety. Pharmacology Biochemistry And Behavior, 100(4), 752-774. http://dx.doi.org/10.1016/j.pbb.2011.04.010

Robinson, S., Alexander, N., Bluett, R., Patel, S., \& McCool, B. (2015). Acute and Chronic Ethanol Exposure Differentially Regulate CB1 Receptor Function at Glutamatergic Synapses in the Rat Basolateral Amygdala. Neuropharmacology. http://dx.doi.org/10.1016/j.neuropharm.2015.12.005

Santesso, D. L., Schmidt, L. A., \& Fox, N. A. (2004). Are shyness and sociability still a dangerous combination for substance use? Evidence from a US and Canadian sample. Personality and Individual Differences, 37, 5-17.

Schneier, F.R., Foose, T.E., Hasin, D.S., Heimberg, .R.G., Liu, S.M., Grant, B.F., \& Blanco, C. (2010). Social anxiety disorder and alcohol use disorder co-morbidity in the National Epidemiologic Survey on Alcohol and Related Conditions. Psychological Medicine, 40, 977988.

Schry, A., \& White, S. (2013). Understanding the relationship between social anxiety and alcohol use in college students: A meta-analysis. Addictive Behaviors, 38(11), 2690-2706. 
http://dx.doi.org/10.1016/j.addbeh.2013.06.014

Smith, J., \& Randall, C. (2012). Anxiety and alcohol use disorders: Comorbidity and treatment considerations. Alcohol Research And Health, 34(4), 414-431.

Span, S. \& Earleywine, M. (1999). Familial risk for alcoholism and hangover symptoms. Addictive Behaviors, 24(1), 121-125. http://dx.doi.org/10.1016/s0306-4603(98)00002-1

Spielberger, C., Gorsuch, R., Lushene, R., Vagg, P., \& Jacobs, G. (1983). Manual for the State-trait anxiety inventory (form Y) ("self-evaluation questionnaire"). Palo Alto, CA: Consulting Psychologists Press.

Strużyńska, L., \& Sulkowski, G. (2004). Relationships between glutamine, glutamate, and GABA in nerve endings under Pb-toxicity conditions. Journal Of Inorganic Biochemistry, 98(6), 951958. http://dx.doi.org/10.1016/j.jinorgbio.2004.02.010

Thomas, S., Randall, C., \& Carrigan, M. (2003). Drinking to Cope in Socially Anxious Individuals: A Controlled Study. Alcoholism: Clinical \& Experimental Research, 27(12), 1937-1943. http://dx.doi.org/10.1097/01.alc.0000100942.30743.8

Weiner, J., \& Valenzuela, C. (2006). Ethanol modulation of GABAergic transmission: The view from the slice. Pharmacology \& Therapeutics, 111(3), 533-554. http://dx.doi.org/10.1016/j.pharmthera.2005.11.002

Young, C., DiBello, A., Traylor, Z., Zvolensky, M., \& Neighbors, C. (2015). A Longitudinal Examination of the Associations Between Shyness, Drinking Motives, Alcohol Use, and Alcohol-Related Problems. Alcoholism: Clinical and Experimental Research, 39(9), 17491755. http://dx.doi.org/10.1111/acer.1279 


\begin{tabular}{|c|c|c|c|}
\hline $\begin{array}{c}\text { Day 1: 6pm } \\
\text { Breathalyser } 1 \\
\text { - Baseline } \\
\text { questionnaires } \\
\text { (shyness, social } \\
\text { phobia, state } \\
\text { anxiety) } \\
\text { (T1) }\end{array}$ & $\begin{array}{l}\text { Day 1: } 8 \text { pm } \\
\text { - Sobergroup: } \\
\text { socialise without } \\
\text { alcohol } \\
\text { - Alcohol group: } \\
\text { socialise and } \\
\text { drink alcohol ad } \\
\text { libitum }\end{array}$ & $\begin{array}{l}\text { Day1: 10pm } \\
\text {-Breathalyser } 2 \\
\text { - Second state } \\
\text { anxiety } \\
\text { questionnaire } \\
\text { (T2) }\end{array}$ & $\begin{array}{c}\text { Day 2: 10am } \\
\text { - Breathalyser } 3 \\
\text { - Third state } \\
\text { anxiety } \\
\text { questionnaire } \\
\text { - AUD } \\
\text { symptoms } \\
\text { questionnaire } \\
\text { (T3) }\end{array}$ \\
\hline
\end{tabular}

Figure 1. A schematic of the experimental procedure, showing measures taken at each of the timepoints (T1-T3) and the experimental manipulation (no alcohol/alcohol).

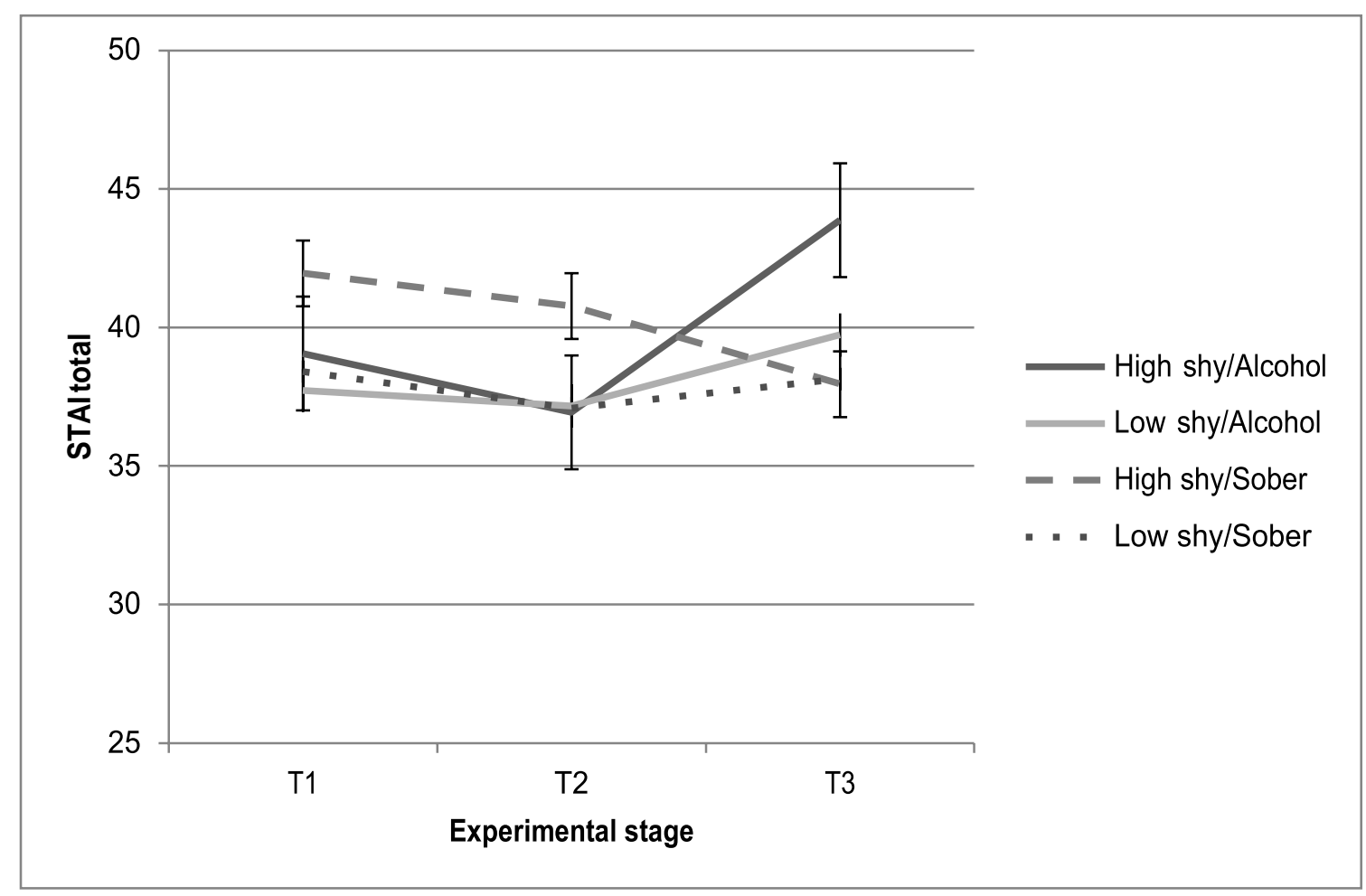

Figure 2. Graph to show mean State-Trait Anxiety Inventory (STAI) scores at each of the three time points (T1: baseline; T2: immediately following drinking period; T3: the following morning) among the four groups. 


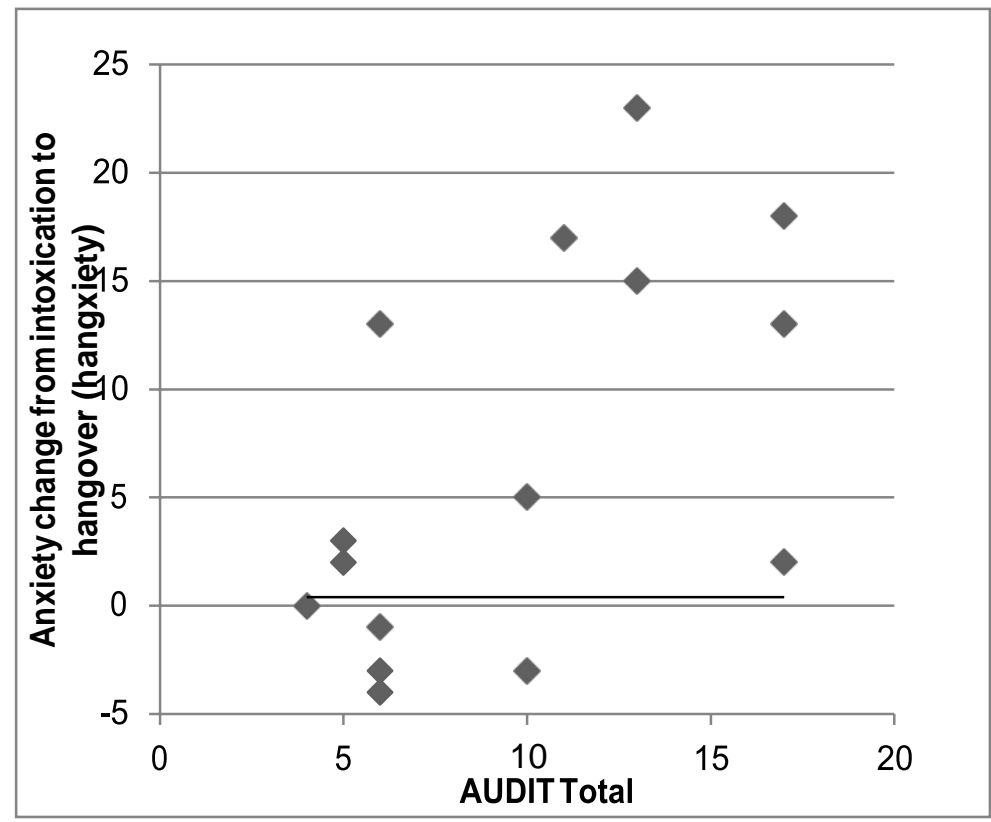

Figure 3. Graph to show the relationship between anxiety change from intoxication to hangover and AUDIT total in the High shy/Alcohol group. Anxiety change score was calculated as STAI score at time 3 - STAI score at time 2. 
Table 1.

Means and standard deviations for demographics, self-reported alcohol use behaviours, tobacco use behaviours, family history of alcoholism and mental health disorder, and baseline assessment scores in

\section{Sober}

n $\quad \operatorname{Mean}(\mathrm{SD})$
Alcohol

$\mathrm{n} \quad \operatorname{Mean}(\mathrm{SD}) \quad t / \chi^{2}$

\section{Demographics}

\begin{tabular}{llllll}
\hline Age & 47 & $23.00(7.98)$ & 50 & $23.44(8.74)$ & -0.26 \\
\hline Education (years) & 47 & $14.89(2.61)$ & 50 & $16.03(1.66)$ & $2.56^{*}$ \\
\hline BMI & 47 & $23.04(4.60)$ & 50 & $23.41(4.65)$ & -0.39 \\
\hline
\end{tabular}

Alcohol use behaviours

\begin{tabular}{lccccc}
\hline Days since last session & 46 & $8.41(9.14)$ & 50 & $1.16(.687)$ & 1.45 \\
\hline No. of units in last session & 46 & $7.49(7.35)$ & 49 & $8.32(6.53)$ & -0.59 \\
\hline Years of regular use & 41 & $6.28(5.50)$ & 50 & $7.42(7.56)$ & -0.81 \\
\hline No. of day used per month & 42 & $5.21(3.53)$ & 44 & $6.89(4.28)$ & 1.97 \\
\hline No. of units in typical session & 47 & $9.30(6.31)$ & 50 & $8.45(4.62)$ & 0.76 \\
\hline
\end{tabular}

Tobacco use behaviours

Regular tobacco use $(\mathrm{y} / \mathrm{n})$ 23 26

0.09

Family history (diagnosed)

\begin{tabular}{lccc}
\hline Alcoholism $(\mathrm{n})$ & 2 & 1 & 1.51 \\
\hline Mental health disorder $(\mathrm{n})$ & 7 & 11 & 0.81 \\
\hline
\end{tabular}

\section{Baseline Assessment}

\begin{tabular}{lccccc}
\hline Shyness Scale & 47 & $52.81(13.7)$ & 50 & $49.36(16.4)$ & 1.12 \\
\hline AUDIT total & 47 & $10.72(6.06)$ & 50 & $10.92(4.99)$ & -0.18 \\
\hline STAI total & 47 & $38.92(7.19)$ & 49 & $37.71(6.38)$ & 0.87 \\
\hline SPIN total & 47 & $20.51(12.5)$ & 50 & $18.98(13.4)$ & 0.58 \\
\hline
\end{tabular}

Note. ${ }^{*} p<.05$. AUDIT, Alcohol Use Disorder Identification Test; STAI, State-Trait Anxiety Inventory; SPIN, Social Phobia Inventory. 
Table 2.

Means and standard deviations for the estimated number of units and drinks consumed during the two-hour drinking session prior to the second anxiety measure and throughout the evening for lowshy and high-shy participants in the alcohol group. No alcohol consumption was reported in the sober group

\begin{tabular}{lclll} 
& Low shy & \multicolumn{2}{l}{ High shy } \\
& Mean(SD) & n & Mean(SD) & $t$ \\
\hline
\end{tabular}

\section{Estimated units}

\begin{tabular}{lrrrrr}
\hline During 2-hour drinking session & 30 & $6.63(3.09)$ & 16 & $6.99(4.85)$ & -3.13 \\
\hline Total across the evening & 30 & $10.41(5.33)$ & 16 & $11.68(7.35)$ & -.670 \\
\hline
\end{tabular}

\section{Estimated drinks}

\begin{tabular}{llllll}
\hline During 2-hour drinking session & 30 & $3.60(1.35)$ & 16 & $4.81(4.52)$ & -1.37 \\
\hline Total across the evening & 30 & $5.97(3.76)$ & 16 & $7.38(5.73)$ & -1.00 \\
\hline
\end{tabular}




\section{Acknowledgements}

This work was supported by an MRC grant (MR L/0230321) to CJAM 
